\title{
Suicidal ideation in patients with mental illness and concurrent substance use: analyses of national census data in Norway
}

\author{
Helle Wessel Andersson ${ }^{1 *}$, Solfrid E. Lilleeng ${ }^{2}$, Torleif Ruud ${ }^{3,4}$ and Solveig Osborg Ose ${ }^{5}$
}

\begin{abstract}
Background: Suicidal ideation may signal potential risk for future suicidal behaviors and death. We examined the prevalence of recent suicidal ideation in patients with mental illness and concurrent substance use and explored the clinical and sociodemographic factors associated with suicidal ideation in this patient subgroup, which represents a particular risk group for adverse psychiatric outcomes.

Methods: We used national cross-sectional census data in Norway collected from 25,525 patients in specialized mental health services. The analytic sample comprised 3,842 patients with concurrent substance use, defined as having a co-morbid substance use disorder or who reported recent regular alcohol use/occasional illicit drug use. Data included suicidal ideation measured in relation to the current treatment episode, sociodemographic characteristics and ICD-10 diagnoses. Bivariate and multivariate analyses were used to examine differential characteristics between patients with and without suicidal ideation.
\end{abstract}

Results: The prevalence of suicidal ideation was $25.8 \%$. The suicidal ideation rates were particularly high for those with personality disorders, posttraumatic stress disorder, and depression, and for alcohol and sedatives compared with other substances. Patients with suicidal ideation were characterized by being younger, having single marital status, and having poorly perceived social relationships with family and friends.

Conclusion: Suicidal ideation in patients with mental illness and concurrent substance use was associated with a number of distinct characteristics. These results might help contribute to an increased focus on a subgroup of individuals at particular risk for suicidality and support suicide prevention efforts in specialized mental health services.

Keywords: Suicidal ideation, Mental disorders, Substance use disorders, Substance use, Mental health services

\section{Background}

Suicidal ideation (SI; thoughts of suicide) may signal a potential risk for future suicide attempts and completed suicide [1-3]. Therefore, as noted by several authors [4, 5] knowledge about the characteristics of individuals who have SI may contribute to the development of targeted

\footnotetext{
*Correspondence: helle.wessel.andersson@stolav.no

${ }^{1}$ Department of Research and Development, Clinic of Substance Use and Addiction Medicine, St. Olavs University Hospital, PB 3250 Sluppen, 7006 Trondheim, Norway

Full list of author information is available at the end of the article
}

interventions addressing this before it progresses to more severe acts.

Mental disorders are strongly associated with suicidal behaviors [6-8]. Clinical studies have repeatedly reported an increased risk of suicidality associated with mood disorders [9-13], personality disorders [10, 12, 13] and anxiety disorders $[13,14]$. In patients with mental illness, concurrent alcohol or drug use may pose an elevated risk of suicidality $[10,15,16]$.

Other risk factors for suicidality include being young and socially disadvantaged $[8,17]$. However, research on

(c) The Author(s) 2022. Open Access This article is licensed under a Creative Commons Attribution 4.0 International License, which permits use, sharing, adaptation, distribution and reproduction in any medium or format, as long as you give appropriate credit to the original author(s) and the source, provide a link to the Creative Commons licence, and indicate if changes were made. The images or other third party material in this article are included in the article's Creative Commons licence unless indicated otherwise in a credit line to the material. If material is not included in the article's Creative Commons licence and your intended use is not permitted by statutory regulation or exceeds the permitted use, you will need to obtain permission directly from the copyright holder. To view a copy of this licence, visit http://creativecommons.org/licenses/by/4.0/. The Creative Commons Public Domain Dedication waiver (http://creativeco mmons.org/publicdomain/zero/1.0/) applies to the data made available in this article, unless otherwise stated in a credit line to the data. 
the impact of sociodemographic factors on risk of suicidality among patients with mental illness has not always been conclusive. For example, among studies on risk factors for SI in the population undergoing mental health treatment, findings were inconsistent regarding educational level: one study found an association between SI and low education [18], while another did not [19]. Furthermore, two studies reported an association between SI and having poor social relationships [12, 19]; however, their results were divergent as to whether this relationship was independent of clinical factors.

Many of those who committed suicide had recently received treatment for mental disorders [3, 20-22]. Therefore, patients currently in specialized mental health treatment comprise an important target group for preventive suicidal measures. Individuals with concurrent substance use constitute a significant part of this patient population [15, 16, 23, 24]. Because individuals with mental illness are particularly vulnerable to negative consequences of substance use [24, 25], a further appropriate targeting of preventive measures would be to address SI in patients under psychiatric care with concurrent substance use.

While there are some studies on risk factors for SI among samples of psychiatric patients with diverse mental disorders $[10-13,16]$, we are aware of only two studies that examined the prevalence of SI in mentally ill patients with concurrent substance use. Both these studies were carried out among patients in acute psychiatric wards, and indicated an increased risk of suicidality associated with concurrent alcohol and drug use $[10,16]$. As far as we know, no previous studies have investigated the clinical and sociodemographic factors associated with SI in general psychiatric patients with concurrent substance use.

Characterizing those who have SI among patients with mental illness and concurrent substance use may be helpful in identifying individuals at suicide risk and contribute to developing suicide prevention efforts within mental health services. Accordingly, the aim of this study was to examine the prevalence of recent SI in psychiatric patients with concurrent substance use by using crosssectional national census data on unselected patients in specialized mental health services in Norway. We have identified and characterized this subsample in a previous publication. Our earlier study showed that compared with patients without substance use, those with concurrent substance use were more socially marginalized (Andersson et al., 2020). This may pose an additional risk for suicidality in this already vulnerable patient group. A particular aim of the current study was to examine the prevalence of and types of mental disorders and substance use associated with recent SI, and the association between sociodemographic factors and SI in this subgroup of patients under psychiatric care.

\section{Methods \\ Setting and design}

The data for our study originate from two datasets based on two national cross-sectional censuses of patients being treated by specialized psychiatric services in Norway. The study setting and design have been described previously [26]. Briefly, one of the censuses was conducted in inpatient wards and departments (including acute wards) to include all patients available on a specific date (November 20, 2012), while the other included all patients receiving treatment at outpatient clinics during a 14-day period (April 15-28, 2013). The two censuses used the same procedures, which justified combining the two datasets to create a gross sample for the current study.

The patients' clinicians were responsible for filling in an anonymous questionnaire for each case based on information from their medical records supplemented with information provided by the patient as part of the study. The questionnaire included data on sociodemographic characteristics, mental health and substance use disorders (SUD) concurrent substance use, social relationships, and suicidality. The Regional Committee for Medical and Health Research Ethics approved the study (reg. no. 2012/848).

\section{Variables \\ Sociodemographic characteristics}

The sociodemographic variables included were age, gender, educational attainment, income, marital status, housing situation and social relationships. Educational attainment was graded as low level (only primary school), medium level (secondary school), or higher level (university or higher education). Income encompassed income from labor, health-related benefits and other economic support. Marital status was classified as: married/cohabitant/partner, separated/divorced/widow(er), or single/ unmarried. Housing situation was classified as: living in owned home, living in rented housing, or without permanent residence (incl. living with family or friends). Information on social relationships was based on the patients' responses to the following two questions: "How is your relationship with your family?" and "How is your relationship with friends?" The questions were answered on a 4-point scale ("very good," "quite good," "quite bad," and "very bad."

\section{Mental disorders}

Information on the main psychiatric diagnosis according to the International Classification of Diseases, ICD10 [27] was collected from the patients' medical records. 
The diagnoses were grouped into the following binary variables $(1=$ presence $0=$ absence): schizophrenia (F20), other psychoses (F22-F25, F28-F29), bipolar disorders (F31), depression (F32-F33), anxiety (F40, F41), eating disorders (F50), personality disorders (F60, F61), and other psychiatric diagnoses or unspecified (i.e., all other F-diagnoses).

\section{Concurrent substance use}

Based on the medical records, the clinicians reported information on the type of SUD diagnosis (ICD-10, F10-F19) recorded as an additional diagnosis (up to two additional diagnoses could be coded). In addition, the clinicians collected data on the patients' substance use (alcohol and/or drugs) during the four weeks preceding treatment (up to three different types of substances used could be recorded), including frequency of use. We defined patients with concurrent substance use as those having either a SUD diagnosis or who reported regular alcohol use/occasional illicit drug use in the last four weeks. Type of concurrent substance used was categorized into the following six binary variables $(1=$ presence; $0=$ absence): alcohol (F10), opioids (F11), cannabis (F12), sedatives (F13), stimulants (F14, F15), or multiple substance use (F19). These criteria for concurrent substance use and characteristics of the sample have been described previously (Andersson et al., 2020).

\section{Suicidal ideation}

Suicidal ideation was identified through a question developed for the National census. The clinicians who were responsible for filling out the mapping form for their patients' were asked to report whether the patient had had any kind of suicidal behavior in the last four weeks. The response options were: "no suicide risk behaviors," "suicidal thoughts," "suicide threats," and "suicide attempts." For the current study, we defined patients with recent SI as those having either suicidal thoughts, threats, or attempts $(1=$ yes $)$, and no SI as those without any suicidal thoughts or behaviors $(0=$ no). Measuring SI by combining thoughts, threats, or attempts is justified by research suggesting that the risk profile of individuals with suicidal thoughts is the same as for those with suicidal behaviors $[28,29]$.

\section{Statistical analyses}

First, based on the gross sample, we compared rates of SI between patients with and without concurrent substance use using chi-square tests. Further analyses were restricted to patients with concurrent substance use (i.e., the analytic sample). Chi-square tests were employed to assess the difference in distribution of the categorical variables (sociodemographic variables and psychiatric diagnoses) between patients with and without SI. Because the psychiatric treatment level (inpatient versus outpatient) might reflect the severity of patients' mental health conditions and sociodemographic characteristics [23] that can influence the prevalence of SI [11], this variable was included in the analysis. We used binary logistic regression analysis to compare the proportion of SI in each substance use category with the proportion of SI in all other substance use categories combined. The estimated odds ratio (OR) and 95\% confidence intervals (CI) with a p-value $<0.05$ indicated that rate of SI in the given substance use category was significantly different from the SI rate in all other substance use categories combined.

To explore the clinical and sociodemographic factors that contributed the most to the difference between patients with and without SI, a multivariate logistic regression was constructed, including variables associated with SI at $\mathrm{p}<0.05$ in bivariate analysis. All analyses were performed using STATA (Stata/SE 16 for Windows; StataCorp LP, College Station, TX, USA).

\section{Results \\ Sample characteristics}

The gross sample comprised 25,525 patients (23,167 outpatients and 2,258 inpatients,) estimated to cover $60 \%$ to $65 \%$ of patients in Norwegian specialized psychiatric services at that time (see Ose et al., 2017). Data on suicidality were missing for 1,265 patients (5\%) and these cases were excluded from the study. The analytic sample consisted of 3,842 patients (751 inpatients and 3,091 outpatients) with concurrent substance use (of whom $30 \%$ with a SUD diagnosis). The analytic sample was the same as that identified and described earlier [23], except that individuals with missing data on suicidality were excluded from the current study $(n=131)$. Briefly, the sample comprised $56 \%$ men and $44 \%$ women, and most were aged $30-39$ years $(23 \%)$ or $>50$ years $(23 \%)$. Most had a low educational level (44\%) and a source of income other than from employment (83\%). In total, 992 (25.8\%) of the patients had SI (suicidal thoughts: 80\%; threats: 12\%; attempts: $8 \%$ ). The SI rate of patients with concurrent substance use was significantly higher than that of nonusers ( $25.8 \%$ vs $18.3 \%$; $\mathrm{p}<0.001$; Table 1$)$.

\section{Bivariate analyses of factors associated with recent $\mathrm{SI}$}

Table 2 presents the clinical and sociodemographic characteristics of patients with and without SI, and the chisquare results for comparisons between these groups. The results of the bivariate analyses revealed that rates for SI varied considerably between the eight specified diagnostic groups. It was most prevalent in patients diagnosed with personality disorders (45.1\%), posttraumatic 
Table 1 Prevalence of suicidal ideation in gross sample and according to patients'substance use status

\begin{tabular}{|c|c|c|c|c|c|c|c|c|c|}
\hline \multirow[t]{2}{*}{ Suicidal ideation status } & \multicolumn{2}{|c|}{$\begin{array}{l}\text { Gross sample } \\
(n=25525)\end{array}$} & \multicolumn{2}{|c|}{$\begin{array}{l}\text { Substance use }{ }^{a} \\
(n=3842)\end{array}$} & \multicolumn{2}{|c|}{$\begin{array}{l}\text { No substance use } \\
(n=20413)\end{array}$} & \multicolumn{3}{|c|}{$\begin{array}{l}\text { Substance use vs no substance } \\
\text { use }\end{array}$} \\
\hline & $\mathrm{n}$ & $\%$ & $\mathbf{n}$ & $\%$ & $\mathbf{n}$ & $\%$ & $x^{2}$ & df & $p$-value \\
\hline $\begin{array}{l}\text { Suicidal } \\
\text { ideation }\end{array}$ & 4730 & 19.5 & 992 & 25.8 & 3738 & 18.3 & & & \\
\hline No suicidal ideation & 19530 & 80.5 & 2850 & 74.2 & 16680 & 81.7 & & & \\
\hline Chi-square test & & & & & & & 109.7 & 1 & $<0.001$ \\
\hline
\end{tabular}

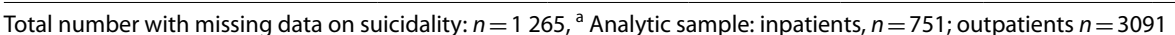

stress disorder (PTSD; 39.3\%), and depression (37.7\%). Further, some but not all sociodemographic categories were significantly associated with the presence of SI. The SI rate was higher in female (27.2\%) than in male subjects (24.0\%), and higher in patients aged $18-23$ years (33.7\%) compared with older age groups. The presence of SI was also associated with marital status and was more common among separated/divorced patients (30.0\%) than among those who were married (23.2\%). Furthermore, SI occurred more frequently in patients who perceived having very poor social relationships to their family (34.5\%) and friends (30.4\%) compared with those who perceived good or very good social relationships. The remaining sociodemographic variables included in the analyseseducation level and main source of income-were not associated with the presence of SI. The treatment-level variable included in the analyses showed that the SI rate was considerably higher among inpatients (33.3\%) than outpatients (24.0\%).

As shown in Table 3, the rates of SI also varied by types of substance use. The SI rates were significantly higher for patients regularly using alcohol $(\mathrm{OR}=1.17 ; \mathrm{p}<0.05)$ and for those using sedatives $(\mathrm{OR}=1.31 ; \mathrm{p}<0.001)$ compared with users of other substances. Patients who were using cannabis were less likely to experience SI $(\mathrm{OR}=0.84$; $\mathrm{p}<0.05)$ compared with users of other substances, as were those using stimulants $(\mathrm{OR}=0.69 ; \mathrm{p}<0.001)$. Many of the patients had more than one SUD diagnosis or more than one substance recorded, indicating combination substance use. A closer look at the data showed that the two most common combinations of substances used was cannabis and stimulants (309 cases) followed by alcohol and cannabis (200 cases).

\section{Results of multivariate analyses}

Table 4 provides the OR values calculated from the multivariable logistic regression model for variables associated with SI in bivariate analyses (Tables 2 and 3). Compared with individuals with a diagnosis of schizophrenia, all of the specified diagnoses, except other psychoses and eating disorders, were associated with higher odds of SI. The odds of SI was particularly high for patients with a personality disorder $(\mathrm{OR}=4.59)$, with PTSD $(\mathrm{OR}=4.64)$ $4.49)$, or with depression $(\mathrm{OR}=4.45)$.

The substances associated with SI in bivariate analysis remained significant in the multivariate model. Compared with all illicit substances, alcohol was associated with a higher odds of SI $(\mathrm{OR}=1.35)$. Compared with alcohol and other illicit drugs, sedatives were associated with a higher odds of SI $(\mathrm{OR}=1.50)$. Stimulant use was associated with a lower odds of SI $(\mathrm{OR}=0.75)$, compared with all other substances.

Among the sociodemographic variables included in the model, age, marital status, and social relationships with friends and family remained significantly associated with having SI. The odds of experiencing SI decreased with age and was highest for individuals aged 18-23 years $(\mathrm{OR}=2.73)$. Compared with patients who were married, being separated was associated with higher odds of SI $(\mathrm{OR}=1.75)$. Compared with patients reporting very good family relationships, the odds of SI increased slightly for each of the alternative response categories: good $(\mathrm{OR}=1.44)$, poor $(\mathrm{OR}=2.09)$ or very poor $(\mathrm{OR}=2.22)$. Furthermore, SI occurred more frequently in patients who perceived having very poor friends relationships $(\mathrm{OR}=1.54)$ compared with those reporting very good friend relationships.

\section{Discussion}

This study adds to existing research examining clinical and sociodemographic factors associated with SI in psychiatric patients with concurrent substance use. We identified several clinical and sociodemographic characteristics associated with SI in this significant subgroup of patients undergoing mental health treatment.

We found that one in four psychiatric patients with concurrent substance use had SI, and the SI rate was considerably higher than that among patients with no substance use. We are not aware of any directly comparable studies; however, our data are consistent with previous research conducted on unselected acutely mentally ill patients that suggested an elevated risk of suicidality in patients with current alcohol or drug use $[10,15,16]$. The 
Table 2 Rates of suicidal ideation according to clinical and sociodemographic characteristics

\begin{tabular}{|c|c|c|c|c|c|c|}
\hline \multirow[t]{2}{*}{ Variables } & \multirow[b]{2}{*}{$N$} & \multirow[b]{2}{*}{$\%$} & \multirow{2}{*}{$\begin{array}{l}\text { Suicidal ideation } \\
\text { rates } \\
\%\end{array}$} & \multicolumn{3}{|c|}{ Chi-square test } \\
\hline & & & & $x^{2}$ & df & $p$-value \\
\hline Diagnoses & & & & 175.14 & 8 & $<.001$ \\
\hline Schizophrenia & 654 & 17.0 & 14.4 & & & \\
\hline Other psychoses & 224 & 5.8 & 15.6 & & & \\
\hline Bipolar disorder & 249 & 6.5 & 23.3 & & & \\
\hline Depression & 624 & 16.2 & 37.7 & & & \\
\hline Anxiety & 288 & 7.5 & 19.1 & & & \\
\hline PTSD & 145 & 3.8 & 39.3 & & & \\
\hline Eating disorders & 68 & 1.8 & 19.1 & & & \\
\hline Personality disorders & 264 & 6.9 & 45.1 & & & \\
\hline Other psychiatric disorders & 1326 & 34.5 & 24.6 & & & \\
\hline Gender & & & & 5.02 & 1 & .025 \\
\hline Male & 2033 & 55.6 & 24.0 & & & \\
\hline Female & 1621 & 44.4 & 27.2 & & & \\
\hline Age group & & & & 30.34 & 4 & $<.001$ \\
\hline $18-23$ years & 572 & 15.3 & 33.7 & & & \\
\hline $24-29$ years & 712 & 19.1 & 26.5 & & & \\
\hline 30-39 years & 872 & 23.4 & 22.6 & & & \\
\hline 40-49 years & 729 & 19.5 & 28.3 & & & \\
\hline$>50$ years & 846 & 22.7 & 22.3 & & & \\
\hline Education & & & & 3.21 & 2 & .201 \\
\hline High & 564 & 15.6 & 29.1 & & & \\
\hline Medium & 1481 & 40.9 & 25.7 & & & \\
\hline Low & 1579 & 43.6 & 25.3 & & & \\
\hline Maine source of income & & & & 3.14 & 2 & .208 \\
\hline From labor & 652 & 17.3 & 27.3 & & & \\
\hline Health related benefit & 2496 & 66.4 & 24.8 & & & \\
\hline Other economic support & 613 & 16.3 & 27.7 & & & \\
\hline Marital status & & & & 8.49 & 2 & .014 \\
\hline Married/cohabitating/partnered & 948 & 24.9 & 23.2 & & & \\
\hline Separated/divorced/widowed & 570 & 15.0 & 30.0 & & & \\
\hline Single/unmarried & 2288 & 60.1 & 25.7 & & & \\
\hline Housing situation & & & & 1.76 & 2 & .415 \\
\hline Owned home & 1317 & 34.9 & 24.7 & & & \\
\hline Rented housing & 1665 & 44.1 & 26.7 & & & \\
\hline Without permanent residence & 791 & 21.0 & 25.2 & & & \\
\hline Social relationships family & & & & 69.75 & 3 & $<.001$ \\
\hline Very good & 963 & 26.4 & 17.4 & & & \\
\hline Good & 1657 & 45.4 & 25.5 & & & \\
\hline Poor & 680 & 18.6 & 33.2 & & & \\
\hline Very poor & 351 & 9.6 & 34.5 & & & \\
\hline Social relationships friends & & & & 20.33 & 3 & $<.001$ \\
\hline Very good & 644 & 18.0 & 20.5 & & & \\
\hline Good & 1578 & 44.0 & 25.1 & & & \\
\hline Poor & 845 & 23.6 & 29.0 & & & \\
\hline Very poor & 519 & 14.5 & 30.4 & & & \\
\hline Treatment level & & & & 26.1 & 1 & $<.001$ \\
\hline Inpatients & 751 & 19.5 & 33.3 & & & \\
\hline Outpatients & 3091 & 80.5 & 24.0 & & & \\
\hline
\end{tabular}


Table 3 Rates of suicidal ideation according types of substances used ${ }^{a}$

\begin{tabular}{|c|c|c|c|c|c|c|}
\hline Types of substances & Patients & $\%^{a}$ & $\mathrm{OR}^{\mathrm{b}}$ & $95 \% \mathrm{Cl}$ & & $p$-value \\
\hline Alcohol (F10) & 1645 & 27.5 & 1.17 & 1.011 & 1.352 & 0.036 \\
\hline Opioids (F11) & 200 & 25.0 & 0.96 & 0.688 & 1.327 & 0.785 \\
\hline Cannabis (F12) & 1169 & 23.6 & 0.84 & 0.720 & 0.991 & .037 \\
\hline Sedatives (F13) & 1071 & 29.7 & 1.31 & 1.122 & 1.538 & $<0.001$ \\
\hline Stimulants (F15) & 727 & 20.5 & 0.69 & 0.571 & 0.846 & $<0.001$ \\
\hline Multiple substance use (F19) & 1049 & 24.4 & 0.90 & 0.766 & 1.063 & 0.217 \\
\hline
\end{tabular}

${ }^{\text {a }}$ Proportion of patients with suicidal ideation within each substance use category

${ }^{b}$ The likelihood of SI in the given substance use category (1) compared with the likelihood in all other substance use categories combined (0)

higher SI rate found among inpatients compared with outpatients was in accord with a previous finding [11], and could be related to different patient compositions found in outpatient versus inpatient units, including more adverse sociodemographic characteristics among inpatients [23].

The most directly comparable research to the present one regarding SI risk associated with diverse mental disorders have been studies conducted among unselected psychiatric samples using similar methodologies with the current study in measuring SI. Our findings of particularly elevated rates of SI associated with depression and personality disorders agree with those previous studies $[10,12,13]$. Moreover, this finding is unsurprising given the higher risk of suicide associated with SUD in these diagnostic groups [30,31]. In addition, our results showed an increased risk of SI among patients diagnosed with PTSD. Previous clinical research has presented mixed results regarding the association between anxiety disorders and SI, possibly because the studies varied in how they defined the diagnostic groups [11-14]. A comprehensive literature review and meta-analysis that included both clinical and general samples suggested that among the anxiety disorders, PTSD was significantly associated with both SI and attempts at suicide [14]. Thus, the risk of suicidality associated with PTSD might have been undetected in previous mental health treatment studies that analyzed the broader ICD-10 category of anxiety disorders [11-13]. Previous research suggested that patients with both SUD and PTSD exhibit more severe substance use [32] and adverse treatment outcomes [33]. Our findings suggest that PTSD and related emotion dysregulation in combination with substance abuse might be associated with an elevated psychological burden and an increased risk of SI in patients under psychiatric care.

Our results showed that alcohol and/or sedatives use were associated with an increased risk of SI compared with other types of drugs (e.g., opioids, cannabis, or stimulants), irrespective of the type of mental illness and sociodemographic characteristics. Both alcohol and sedatives (e.g., benzodiazepines) are central nervous system depressants associated with an elevated risk of suicidal behaviors, compared with other types of drugs [34]. In patients with mental disorders, especially depression, use of alcohol may indicate greater serotonergic impairment, which might be associated with more negative mood states and increased risk for suicidality [35]. Moreover, in this population, the use of benzodiazepines in particular might be associated with an increased risk of suicidality [36]. On the other hand, among mentally ill patients with SI, readily available substances such as alcohol and sedatives may be used as a means of reducing psychological pain and psychosocial stressors associated with the mental disorder and a difficult life situation. Adverse psychosocial factors remained independently associated with SI in the multivariate model, which supports this latter assumption. The current findings of an increased SI risk associated with adverse sociodemographic factors align with previous findings from mental health treatment samples [10, 12, 13, 18, 19]. Our study contributes to existing knowledge by suggesting that among patients with concurrent substance, those with younger age, single marital status and poor social relationships may have a further elevated SI risk. Based on the current findings, it may be suggested that measures aimed at those who suffer social marginalization may reduce suicidal thoughts and future suicide attempts in this particularly vulnerable patient group.

\section{Strengths and limitations}

A main strength of the current study was the large sample size, including both outpatients and inpatients with concurrent substance use in specialized mental health care clinics. The study focused on a significant subgroup of patients undergoing specialized mental health treatment, who, despite their increased risk of severe psychiatric outcome [24, 25, 37], have received relatively little attention in previous research on SI. The large sample size enabled analyses with a relatively detailed categorization of 
Table 4 Multivariate analyses of factors associated with suicidal ideation

\begin{tabular}{|c|c|c|c|c|}
\hline \multirow{2}{*}{$\begin{array}{l}\text { Variables } \\
\text { Diagnoses: Base: Schizophrenia }\end{array}$} & \multirow[t]{2}{*}{ OR } & \multicolumn{2}{|l|}{$95 \% \mathrm{Cl}$} & \multirow[t]{2}{*}{$p$-value } \\
\hline & & & & \\
\hline Other psychoses & 1.19 & 0.742 & 1.906 & 0.472 \\
\hline Bipolar disorder & 2.15 & 1.391 & 3.323 & 0.001 \\
\hline Depression & 4.45 & 3.157 & 6.260 & $<.001$ \\
\hline Anxiety & 1.98 & 1.303 & 3.016 & 0.001 \\
\hline PTSD & 4.64 & 2.923 & 7.377 & $<.001$ \\
\hline Eating disorders & 1.64 & 0.800 & 3.350 & 0.177 \\
\hline Personality disorders & 4.59 & 3.107 & 6.784 & $<.001$ \\
\hline Other psychiatric disorders & 2.15 & 1.589 & 2.909 & $<.001$ \\
\hline \multicolumn{5}{|c|}{ Types of substances used: Dummies ${ }^{\mathrm{a}}$} \\
\hline Alcohol (F10) & 1.35 & 1.094 & 1.676 & 0.005 \\
\hline Cannabis (F12) & 0.90 & 0.720 & 1.137 & 0.389 \\
\hline Sedatives (F13) & 1.50 & 1.203 & 1.871 & $<.001$ \\
\hline Stimulants (F15) & 0.75 & 0.588 & 0.963 & 0.024 \\
\hline \multicolumn{5}{|l|}{ Gender: Base: Male } \\
\hline Female & 1.01 & 0.842 & 1.207 & 0.930 \\
\hline \multicolumn{5}{|l|}{ Age: Base: $>50$ years } \\
\hline $18-23$ years & 2.73 & 1.964 & 3.803 & $<.001$ \\
\hline $24-29$ years & 2.17 & 1.602 & 2.949 & $<.001$ \\
\hline 30-39 years & 1.60 & 1.195 & 2.131 & 0.002 \\
\hline $40-49$ years & 1.81 & 1.376 & 2.371 & $<.001$ \\
\hline \multicolumn{5}{|c|}{ Marital status: Base: Married/ partner } \\
\hline Separated/divorced/widow(er) & 1.75 & 1.322 & 2.310 & $<.001$ \\
\hline Single/unmarried & 1.24 & 0.993 & 1.547 & 0.058 \\
\hline \multicolumn{5}{|c|}{ Family relationships: Base: Very good } \\
\hline Good & 1.44 & 1.147 & 1.821 & 0.002 \\
\hline Poor & 2.09 & 1.590 & 2.735 & $<.001$ \\
\hline Very poor & 2.22 & 1.590 & 3.105 & $<.001$ \\
\hline \multicolumn{5}{|c|}{ Friends relationships: Base: Very good } \\
\hline Good & 1.18 & 0.912 & 1.522 & 0.209 \\
\hline Poor & 1.31 & 0.975 & 1.748 & 0.073 \\
\hline Very poor & 1.54 & 1.106 & 2.158 & 0.011 \\
\hline \multicolumn{5}{|l|}{ Treatment level: Base: Outpatient } \\
\hline Inpatient & 2.02 & 1.607 & 2.550 & $<.001$ \\
\hline Constant & 0.03 & 0.016 & 0.048 & $<.001$ \\
\hline
\end{tabular}

Log likelihood $=-1706.9628, \mathrm{Chi}=308.34(p<.0001), N=3274$

${ }^{a}$ The proportion of SI in the given substance use category (1) compared with the proportion of SI in all other substance use categories combined (0)

patients according to types of mental disorders and substances used. The study also included relatively detailed information on sociodemographic characteristics, some of which have been considered by only a few previous studies of SI among patients with mental disorders.

The study had several limitations. We combined datasets from cross-sectional censuses conducted in psychiatric inpatient and outpatient wards and departments. Because of a time gap of about 5 months between the two censuses, a patient who were included in the mapping while in inpatient treatment may later have received outpatient treatment. According to a Norwegian report from the census, $8 \%$ of the outpatients received inpatient treatment during the last quarter of the previous year [38]. Hence, a maximum of 247 outpatients in the current study could potentially been mapped twice. This means we cannot rule out a potential bias of dependent observations. The cross-sectional design of the study precluded any causal inferences. The study included several non-validated measures. Information on SI in the patients was based on the clinicians' reports, as has been done previously [16]. According to national guidelines for prevention of suicide in specialized mental health services, the clinicians should routinely perform suicide risk assessment as part of the psychiatric evaluation [39]. Because the use of such routinely collected data is appropriate, especially in conducting large-scale studies, future research on suicidality among patients under psychiatric care should examine the validity of the medical record information on suicidality provided by clinicians. Further, concurrent substance use was defined as having a SUD diagnosis or recent regular alcohol use/occasional drug use. While a SUD diagnosis was based on ICD-10 criteria, information on alcohol/drug use was based on the patient-reported substance use data collected by the responsible clinician. The use of standardized screening instruments for substance use, such as for example the alcohol and drug use identification tests (AUDIT and DUDIT), might have provided more valid measures of substance use in this study. The current study also used a non-validated scale to assess the patients' ratings of their relationships with friends and family. Because social relationships appear to play an important role in the prevalence of SI in this population, future research could examine the significance of this finding in more detail using validated instruments.

\section{Conclusion}

Patients with mental illness and concurrent substance use have an increased probability of experiencing SI. The risk of SI is particularly high in patients diagnosed with personality disorder, PTSD or depression. In addition, our findings suggest that patients who are socially marginalized, or below 30 years of age may have a further elevated SI risk. Patients with these characteristics might need special attention to prevent future more severe forms of suicidal behaviors.

\section{Abbreviations}

SI: Suicidal ideation; SUD: Substance use disorders; PTSD: Posttraumatic stress disorder; ICD-10: International Statistical Classification of Diseases and Related Health Problems $10^{\text {th }}$ version; WHO: World Health Organization; OR: Odds 
ratio; Cl: Confidence interval; AUDIT: Alcohol Use Disorders Identification Test; DUDIT: Drug Use Disorder Identification Test.

\section{Acknowledgements}

We would like to thank the personnel in the psychiatric wards and departments for facilitating the data collection, and for their contribution to this research. The Norwegian Directorate of Health funded the data collection.

\section{Authors' contributions}

HWA wrote the main manuscript text. SEL supervised the analyses and interpretation of data. TR critically reviewed and revised the manuscript. SO carried out the statistical analyses. All authors reviewed the manuscript. The author(s) read and approved the final manuscript.

\section{Funding}

No funding was provided for this study.

\section{Availability of data and materials}

The data that support the findings of this study are available from author SOO upon reasonable request.

\section{Declarations}

\section{Ethics approval and consent to participate}

This study comprised full mapping of patients in all psychiatric wards and departments conducted on behalf of the national health authorities. Each patient's clinician was responsible for completing one form per patient. Informed consent was obtained from the patients, but the clinician completed the forms for all patients, including those who did not give their consent. In the latter case, no personal identification number was collected. Data was anonymized for the analyses. The study was approved by The Regional Committee for Medical and Health Research Ethics (reg.no. 2012/848). All methods were performed in accordance with the relevant guidelines and regulations.

\section{Consent for publication}

Not applicable.

\section{Competing interests}

The authors declare that they have no competing interests.

\begin{abstract}
Author details
'Department of Research and Development, Clinic of Substance Use and Addiction Medicine, St. Olavs University Hospital, PB 3250 Sluppen, 7006 Trondheim, Norway. ${ }^{2}$ Department of Analysis and Performance Assessment, The Norwegian Directorate of Health, Holtermanns vei 70, 7031 Trondheim, Norway. ${ }^{3}$ Akershus University Hospital, Mental Health Services, PB 10001478 Lørenskog, Norway. ${ }^{4}$ Institute of Clinical Medicine, University of Oslo, PB 1171 Blindern, 0318 Oslo, Norway. ${ }^{5}$ Department of Health, SINTEF, Professor Brochs gate 2, 7030 Trondheim, Norway.
\end{abstract}

Received: 8 September 2021 Accepted: 20 December 2021 Published online: 04 January 2022

\section{References}

1. Hubers A, Moaddine S, Peersmann S, Stijnen T, Van Duijn E, Van der Mast $R$, et al. Suicidal ideation and subsequent completed suicide in both psychiatric and non-psychiatric populations: a meta-analysis. Epidemiol Psychiatr Sci. 2018;27(2):186.

2. Rossom RC, Coleman KJ, Ahmedani BK, Beck A, Johnson E, Oliver M, et al. Suicidal ideation reported on the PHQ9 and risk of suicidal behavior across age groups. J Affect Disord. 2017;215:77-84.

3. Chung D, Ryan CJ, Hadzi-Pavlovic D, Singh SP, Stanton C, Large MM. Suicide rates after discharge from psychiatric facilities: a systematic review and meta-analysis. JAMA Psychiat. 2017;74(7):694-702.

4. Jobes DA, Joiner TE. Reflections on suicidal ideation. Crisis. 2019;40(4):227-30.
5. Kleiman EM. Suicidal thinking as a valuable clinical endpoint. EClinicalMedicine. 2020;23:100399.

6. Nock MK, Hwang I, Sampson N, Kessler RC, Angermeyer M, Beautrais $A$, et al. Cross-national analysis of the associations among mental disorders and suicidal behavior: findings from the WHO World Mental Health Surveys. PLoS Med. 2009;6(8):e1000123

7. Nock MK, Hwang I, Sampson NA, Kessler RC. Mental disorders, comorbidity and suicidal behavior: results from the National Comorbidity Survey Replication. Mol Psychiatry. 2010;15(8):868-76.

8. O'Connor RC, Nock MK. The psychology of suicidal behaviour. Lancet Psychiatry. 2014;1(1):73-85.

9. Naragon-Gainey K, Watson D. The anxiety disorders and suicidal ideation: accounting for co-morbidity via underlying personality traits. Psychol Med. 2011;41(7):1437-47.

10. Sørlie T, Sørgaard KW, Bogdanov A, Bratlid T, Rezvy G. Prevalence and characteristics of suicide attempters and ideators among acutely admitted psychiatric hospital patients in northwest Russia and northern Norway. BMC Psychiatry. 2015;15(1):1-9.

11. Baldessarini R, Tondo L. Suicidal risks in 12 DSM-5 psychiatric disorders. J Affec Disord. 2020;271:66-73.

12. Ose SO, Tveit T, Mehlum L. Non-suicidal self-injury (NSSI) in adult psychiatric outpatients-A nationwide study. J Psychiatr Res. 2021;133:1-9.

13. Furnes D, Gjestad R, Rypdal K, Mehlum L, Hart S, Oedegaard KJ, et al. Suicidal and violent ideation in acute psychiatric inpatients: prevalence, co-occurrence, and associated characteristics. Suicide and Life Threat Behav. 2020;51(3):528-39.

14. Bentley KH, Franklin JC, Ribeiro JD, Kleiman EM, Fox KR, Nock MK. Anxiety and its disorders as risk factors for suicidal thoughts and behaviors: A meta-analytic review. Clinical Psychol Rev. 2016;43:30-46.

15. Ries RK, Yuodelis-Flores C, Roy-Byrne PP, Nilssen O, Russo J. Addiction and suicidal behavior in acute psychiatric inpatients. Compr Psychiatry. 2009;50(2):93-9.

16. McCloud A, Barnaby B, Omu N, Drummond C, Aboud A. Relationship between alcohol use disorders and suicidality in a psychiatric population: in-patient prevalence study. Br J Psychiatry. 2004;184(5):439-45.

17. Haw C, Hawton K. Living alone and deliberate self-harm: a case-control study of characteristics and risk factors. Soc Psychiatry Psychiatr Epidemiol. 2011;46(11):1115-25.

18. Trivedi MH, Morris DW, Wisniewski SR, Nierenberg AA, Gaynes BN, Kurian BT, et al. Clinical and sociodemographic characteristics associated with suicidal ideation in depressed outpatients. Can J Psychiatry. 2013;58(2):113-22.

19. Hintikka J, Viinamäki H, Koivumaa-Honkanen H-T, Saarinen P, Tanskanen A, Lehtonen J. Risk factors for suicidal ideation in psychiatric patients. Soc Psychiatry Psychiatr Epidemiol. 1998;33(5):235-40.

20. Stene-Larsen K, Reneflot A. Contact with primary and mental health care prior to suicide: a systematic review of the literature from 2000 to 2017. Scand J Public Health. 2019;47(1):9-17.

21. Walby FA, Myhre MØ, Kildahl AT. Contact with mental health services prior to suicide: a systematic review and meta-analysis. Psychiatr Serv. 2018;69(7):751-9.

22. Chen $Q$, Zhang-James Y, Barnett EJ, Lichtenstein P, Jokinen J, D'Onofrio $\mathrm{BM}$, et al. Predicting suicide attempt or suicide death following a visit to psychiatric specialty care: A machine learning study using Swedish national registry data. PLoS Med. 2020;17(11):e1003416.

23. Andersson HW, Lilleeng SE, Ruud T, Ose SO. Substance use among patients in specialized mental health services in Norway: prevalence and patient characteristics based on a national census. Nord J Psychiatry. 2020;75(3):160-9.

24. Lagerberg TV, Andreassen OA, Ringen PA, Berg AO, Larsson S, Agartz I, et al. Excessive substance use in bipolar disorder is associated with impaired functioning rather than clinical characteristics, a descriptive study. BMC Psychiatry. 2010;10(1):1-9.

25. Hulse G, Saunders J, Roydhouse R, Stockwell T, Basso M. Screening for hazardous alcohol use and dependence in psychiatric in-patients using the AUDIT questionnaire. Drug Alcohol Rev. 2000;19(3):291-8.

26. Ose SO, Lilleeng S, Pettersen I, Ruud T, van Weeghel J. Risk of violence among patients in psychiatric treatment: results from a national census. Nord J Psychiatry. 2017;71(8):551-60. 
27. WHO. The ICD10 Classification of Mental and Behavioral Disorders: Clinical Descriptions and Diagnostic Guidelines. Geneva, Switzerland: World Health Organization; 1992

28. Large M, Corderoy A, McHugh C. Is suicidal behaviour a stronger predictor of later suicide than suicidal ideation? A systematic review and metaanalysis. Aust N Z J Psychiatry. 2021;55(3):254-67.

29. Øiesvold T, Bakkejord T, Hansen V, Nivison M, Sørgaard KW. Suicidality related to first-time admissions to psychiatric hospital. Soc Psychiatry Psychiatr Epidemiol. 2012;47(3):419-25.

30. Østergaard ML, Nordentoft M, Hjorthøj C. Associations between substance use disorders and suicide or suicide attempts in people with mental illness: a Danish nation-wide, prospective, register-based study of patients diagnosed with schizophrenia, bipolar disorder, unipolar depression or personality disorder. Addiction. 2017;112(7):1250-9.

31. Carrà G, Bartoli F, Crocamo C, Brady KT, Clerici M. Attempted suicide in people with co-occurring bipolar and substance use disorders: systematic review and meta-analysis. J Affect Disord. 2014;167:125-35.

32. Najavits LM. Creating change: A new past-focused model for trauma and substance abuse. In: Ouimette P, Read JP, editors. Trauma and substance abuse: Causes, consequences, and treatment of comorbid disorders: Americal Psychological Association; 2014. p. 281-303

33. Westphal M, Aldao A, Jackson C. Emotion dysregulation in comorbid posttraumatic stress disorder and substance use disorders: A narrative review. Mil Psychol. 2017;29(3):216-

34. Wines JD Jr, Saitz R, Horton NJ, Lloyd-Travaglini C, Samet JH. Suicidal behavior, drug use and depressive symptoms after detoxification: a 2-year prospective study. Drug Alcohol Depend. 2004;76:S21-9.

35. Mann JJ. The serotonergic system in mood disorders and suicidal behaviour. Philos Trans R Soc Lond B Biol Sci. 2013. https://doi.org/10.1098/rstb. 2012.0537.

36. Cato V, Holländare F, Nordenskjöld A, Sellin T. Association between benzodiazepines and suicide risk: a matched case-control study. BMC Psychiatry. 2019;19(1):1-7.

37. Mueser KT, Drake RE, Wallach MA. Dual diagnosis: a review of etiological theories. Addict Behav. 1998;23(6):717-34.

38. Ose SO, Ådnanes M, Pettersen I. Poliklinske pasienter i psykisk helsevern for voksne 2013. [Outpatiens in specialized mental health services 2013] Trondheim, Norway: SINTEF Teknologi og samfunn.

39. Norwegian Directorate of Health. Nasjonale retningslinjer for forebygging av selvmord i psykisk helsevern. [National guidelines for prevention of suicide in specialized mental health services]. 2008.

\section{Publisher's Note}

Springer Nature remains neutral with regard to jurisdictional claims in published maps and institutional affiliations.

Ready to submit your research? Choose BMC and benefit from:

- fast, convenient online submission

- thorough peer review by experienced researchers in your field

- rapid publication on acceptance

- support for research data, including large and complex data types

- gold Open Access which fosters wider collaboration and increased citations

- maximum visibility for your research: over $100 \mathrm{M}$ website views per year

At BMC, research is always in progress.

Learn more biomedcentral.com/submissions 